\title{
INTERAÇÕES ENTRE CIÊNCIA E TECNOLOGIA: análise da produção intelectual dos pesquisadores-inventores da primeira carta-patente da UFRGS ${ }^{*}$
}

\author{
INTERACTIONS BETWEEN SCIENCE AND TECHNOLOGY: analysis of the \\ intellectual production of the researchers-inventors of the first letter-patent of \\ the UFRGS
}

Ana Maria Mielniczuk de Moura - ana.moura@ufrgs.br

Mestre em Comunicação e Informação

Helen Beatriz Frota Rozados - hrozados@gmail.com

Doutora em Comunicação e Informação

Sônia Elisa Caregnato - caregnat@ufrgs.br

Doutora em Information Science (Sheffield University)

Professoras da Faculdade de Biblioteconomia e Comunicação da UFRGS

\section{Resumo}

Comente este artigo no blog Ebibli = http://encontros-bibli-blog.blogspot.com/

Discute questões como propriedade intelectual e industrial e diferenças existentes entre conhecimento científico e tecnológico. Busca inserir a patente no contexto da comunicação científica e tecnológica. Apresenta dados de um estudo que objetiva analisar a relação entre a informação científica e a tecnológica na produção intelectual dos pesquisadores-inventores da primeira carta-patente da Universidade Federal do Rio Grande do Sul (UFRGS). O período analisado compreende os anos anteriores à publicação do pedido da patente (1996-2000) e posteriores (2001-2005). Conclui que, no caso analisado, ocorre um fluxo entre a informação científica e tecnológica, na qual a primeira, após sua divulgação e aprovação pelos pares, subsidia a segunda. Da mesma forma, a patente gera um impacto na produção científica dos pesquisadores, ocorrendo uma retroalimentação entre ciência e tecnologia. Sugere que novos estudos sejam realizados.

Palavras-chave: Patentes. Propriedade Intelectual. Propriedade Industrial. Produção Intelectual. Comunicação Científica.

\section{INTRODUÇÃO}

A competitividade global trouxe reflexos imediatos para as atividades de informação tecnológica. Quanto mais ocorre a abertura dos mercados mundiais, mais os aspectos da qualidade e da inovação tornam-se críticos para o desenvolvimento econômico de um país. No processo de inovação tecnológica, as invenções e as inovações são fundamentais e, com isso, as patentes constituem-se em elementos importantes do Sistema Internacional de Propriedade Industrial.

- Versão preliminar deste trabalho foi apresentada no VI ENANCIB - Encontro Nacional de Pesquisa em Ciência da Informação, realizado em Florianópolis, de 28 a 30 de novembro de 2005. 
A discussão sobre a importância das patentes como fonte de informação tecnológica para o desenvolvimento social e econômico de um país e a sua inserção no processo de comunicação científica propicia a percepção de aspectos relevantes sobre o conhecimento científico e o conhecimento tecnológico, colocando a informação como base para a inovação. Parte-se de um levantamento de dados, no âmbito da Universidade Federal do Rio Grande do Sul (UFRGS), de caráter descritivo, de forma a verificar a relação entre ciência e tecnologia na produção científica e tecnológica de pesquisadores da UFRGS. A amostra utilizada para esta análise foram os pesquisadores envolvidos na obtenção da primeira carta-patente da UFRGS, que teve seu pedido publicado no INPI em 2000, e a concessão da carta em 2002, tomando-se para a análise os 5 anos anteriores à publicação do pedido e os 5 posteriores, ou seja, o período que compreende os anos de 1996 a 2000 e 2001 a 2005. Faz-se uso da análise de conteúdo para confrontar as palavras-chave retiradas da patente com a produção científica.

\section{A PATENTE COMO FONTE DE INFORMAÇÃO TECNOLÓGICA}

O Sistema Internacional de Propriedade Industrial é considerado como o conjunto de leis e tratados que tem o objetivo de proteger todas as formas de ativos intangíveis da indústria, ou seja, a riqueza não-material gerada paralelamente à fabricação de bens materiais, e representada por valores voláteis, tais como a tecnologia utilizada, o conceito da empresa junto à clientela, o seu reconhecimento frente aos concorrentes, entre outros.

O instrumento de Patente de Invenção (criações no campo da tecnologia) constitui-se em um dos principais componentes deste sistema, que engloba também a patente de Modelo de Utilidade (melhorias efetuadas em produtos já existentes), a Marca de Negócio (símbolos ou sinais perceptíveis visualmente) e o Registro de Desenho Industrial (forma plástica ornamental de um objeto ou conjunto ornamental de linhas e cores que servem de tipo para fabricação industrial).

O sistema de propriedade intelectual teve seus princípios básicos estabelecidos na Convenção da União de Paris para Proteção da Propriedade Industrial, mais comumente conhecida como União de Paris. São eles: o tratamento nacional, o direito de prioridade e a independência do privilégio. No Brasil, a Lei 9.279/1996, que trata da propriedade industrial, foi promulgada para atender as exigências do acordo TRIPS (Trade-related Aspects of Intellectual Property Rights) sobre o comércio internacional. Esta lei especifica que as 
validades máximas de duração da proteção da patente são de 20 anos para a patente de invenção e de 15 anos para a patente de modelo de utilidade.

A lei estabelece, também, o que pode ou não ser patenteável, pois a patente deve representar uma invenção, ou seja, ela não deve ser naturalmente deduzida do estágio atual da técnica. Além disso, ela deve necessariamente ter alguma aplicação industrial. Desta forma, criações intelectuais, tais como teorias científicas, métodos matemáticos, programas de computador e as criações estéticas, não são patenteáveis. Em geral, considera-se ainda como não patenteável o que for contrário à segurança e à saúde públicas, bem como os seres vivos e materiais biológicos como são encontrados na natureza (França, 2000).

A patente é, em tese, a mais importante fonte primária de informação tecnológica, pois permite o conhecimento de inovações fundamentais para a indústria, após a descrição original do invento. Infelizmente, tem sido constatado, conforme França (2000), que raramente ela é levada em consideração no momento da busca de informações técnicas, em que pese o alto percentual de $95 \%$ das patentes válidas nos países industrializados serem de domínio público nos demais, podendo ser livremente usadas.

O documento de patente é um elemento primordial para o desenvolvimento econômico de países em desenvolvimento como o Brasil, pois, além do alto percentual de patentes válidas nos países desenvolvidos não serem protegidas aqui, mais de $99 \%$ dos pedidos de patente depositados são modificações de patentes já existentes: "Assim, não temos a menor dúvida que um esforço conjunto do setor produtivo e das instituições de $\mathrm{P} \& \mathrm{D}$, no sentido de utilizar a informação de patentes, poderá dar ao Brasil um de seus mais importantes instrumentos de desenvolvimento" (ARAÚJO, 1984, p. 56).

Soma-se a isso o fato de a patente ser o instrumento através do qual o conhecimento tecnológico assume o papel de um bem econômico, possuindo três funções básicas, conforme aponta Araújo (1984): a) do ponto de vista técnico, pode fixar de forma minuciosa o estado da arte desta técnica em um dado momento e, consequentemente, pela descrição precisa e detalhada que faz, permitir sua difusão através da publicação do pedido/patente; b) no plano legal, protege o inventor da exploração abusiva da novidade, conferindo-lhe um direito de propriedade exclusivo, mais ou menos extenso, segundo a área de proteção requerida; c) sob o ângulo econômico, permite ao inventor rentabilizar sua descoberta, explorando-a diretamente, ou, na impossibilidade de fazê-lo, de forma indireta, através de licenciamento.

Sabe-se que as patentes constituem uma das mais antigas formas de proteção da propriedade intelectual e, como em todas as formas de proteção da propriedade intelectual, a finalidade de um sistema de patentes é incentivar o desenvolvimento econômico e 
tecnológico, recompensando a criatividade. Estas são razões que, por si só, justificam a importância da patente .A patente insere-se no contexto das discussões sobre propriedade intelectual também como um importante instrumento na valorização dos ativos intangíveis, indispensáveis para o desenvolvimento econômico e social, como apontam Buainain et al (2003?)

Neste contexto, cresce a importância da propriedade intelectual como instituição necessária para dar proteção e facilitar a valorização econômica dos ativos intangíveis. Ainda que insuficiente, não pode ser desconsiderada a importância dos estatutos de proteção legal da propriedade intelectual. Ao contrário, considera-se que os mesmos são condição essencial para o funcionamento eficaz das economias contemporâneas, principalmente no estágio atual, no qual ativos intangíveis na forma de conhecimento científico e tecnológico são vistos como os propulsores do crescimento e desenvolvimento econômico e social.

Embora a importância da utilização das patentes seja inegável, algumas restrições podem contribuir para a explicação da sua pouca utilização. A maior das restrições é o desconhecimento do tipo e da estruturação da informação contida nas cartas-patente. Além disso, conforme França (2000), embora muitas pessoas acreditem que as informações relevantes ali publicadas estarão disponíveis em outras fontes de informação, apenas uma parcela mínima dessas informações são divulgadas em qualquer outro meio, o que torna os documentos de patente, muitas vezes, a única forma de se chegar a elas. Outra questão a ser colocada refere-se ao volume de patentes, que aumenta a cada dia: são publicados, anualmente, mais de um milhão de solicitações, embora o número real de invenções seja menor, em função das famílias de patentes.

Uma hipótese para a subutilização das patentes é seu formato. Para que isto seja resolvido, acordos como o Tratado de Cooperação de Patentes, administrado pelo International Bureau of the World Intelectual Property Organization (WIPO) e do Paris Union Committee of the International Standards Organization e o European Conference estão preocupadas em normatizar este tipo de documentação visando, principalmente, facilitar a recuperação das informações nelas contidas.

Além de todas essas restrições ao uso, sabe-se, ainda, que a patente é depositada antes que o invento possa ser comercialmente explorado, nada garantindo o sucesso futuro de sua exploração, o que traz um importante elemento de incerteza quanto à sua utilidade.

Essas razões justificam a importância da patente na construção do conhecimento tecnológico, apesar das restrições ao seu uso. Assim, ficam as questões: qual a importância das patentes na construção do conhecimento científico? E, inversamente, de que forma o conhecimento científico se transforma em patentes? Estas questões permeiam a informação 
científica e tecnológica no âmbito da comunicação científica, tópicos a serem abordados a seguir.

\section{INFORMAÇÃO TECNOLÓGICA E INFORMAÇÃO CIENTÍFICA: APROXIMAÇÕES NO CONTEXTO DA COMUNICAÇÃO CIENTÍFICA}

Historicamente, observa-se uma separação clara entre o que constitui o conhecimento tecnológico e o conhecimento científico, a começar pela sua conceituação. Uma definição atualizada de informação tecnológica, elaborada por Álvares (1998, p. 66), estabelece que ela constitui-se em: "Todo tipo de conhecimento sobre tecnologias de processo, de produto e de produção que favoreça a melhoria contínua da qualidade e a inovação no setor produtivo". Já o conhecimento científico, de acordo com Stumpf (2000, p. 108), é obtido:

[...] mediante a investigação científica que tem a comunicação como fator inerente à sua natureza e à sua prática. À sua natureza, porque a investigação científica que não é comunicada não existe, e à sua prática porque a comunicação está no âmago do método científico que, para ser seguido, exige a consulta aos trabalhos anteriores e conclui com a divulgação dos resultados.

Este conhecimento gerado precisa, então, ser divulgado entre os pares, para que possa ser validado. Esta é uma das grandes diferenças existentes entre o conhecimento científico e o tecnológico, pois a avaliação pelos pares, existente na validação do conhecimento científico, não se aplica à validação do conhecimento tecnológico.

Um dos aspectos convergentes entre esses dois tipos de conhecimento diz respeito à divulgação. Ambos possuem o mesmo objetivo: garantir a prioridade. Porém, a motivação para a divulgação é, muitas vezes, um aspecto divergente em ambos. A divulgação do conhecimento científico pode servir para firmar a reputação do pesquisador em seu meio de atuação, ou conforme Silva, Menezes e Pinheiro (2003, p. 1): “A publicação de resultados de pesquisa garante a sobrevivência do pesquisador no meio científico pois garante os recursos públicos para o financiamento da pesquisa".

Já a divulgação do conhecimento tecnológico constitui-se em um processo necessário para a proteção do valor econômico da informação, por meio do registro da patente, marca, desenho ou outra forma de registro, não importando a opinião ou validação dos seus pares, apenas do órgão que fará o registro, caso a inovação atenda aos requisitos necessários.

Costa (2000) argumenta que, por sua complexidade, o estudo do processo de comunicação científica envolve um variado número de questões, que incluem tanto o processo em seu todo, como cada uma de suas funções em particular. Compreende, ainda, o estudo de 
seus diferentes atores, de comunidades científicas como principal locus em que as interações entre pares ocorrem a infra-estrutura de informação, a comunicação mediada por computador, entre outros.

Estes aspectos, abordados pela comunicação científica, não encontram similares em estudos sobre informação tecnológica. Não há relatos de estudos que investiguem como se dá o processo de comunicação entre pesquisadores envolvidos em criações tecnológicas. Contudo, estes mesmos pesquisadores, muitas vezes, além de possuírem patentes registradas fazem parte de uma comunidade científica, estão ligados a uma universidade e têm publicações científicas em seu currículo. Já os pesquisadores vinculados somente a empresas, geralmente limitam-se à criação necessária à produção industrial, o que acaba resultando na proteção deste invento, através do documento patente.

Para a obtenção da patente, dois pontos importantes devem ser abordados, uma vez que eles comprometem a disseminação da informação contida neste tipo de documento. Um deles é a divulgação, através da publicação científica, que não pode acontecer devido ao sigilo; outro tem a ver com a necessária novidade que envolve o objeto a ser patenteado. Acredita-se que estes aspectos influenciem esta área que envolve a criação do conhecimento tecnológico, tornando-a não muito aberta a estudos que desvende comportamentos relacionados à construção do conhecimento. Por estar envolta num manto de segredo industrial, no qual não é permitido que o concorrente tenha acesso a detalhes dos projetos, a interação, muito comum no âmbito da construção do conhecimento científico, não ocorre nesta área.

Em face da recente e ampla discussão sobre a necessidade de se buscar o acesso aberto ao conhecimento científico produzido com recursos públicos (SUBER, 2003; THE UNITED KINGDON PARLIAMENT, 2004; MORENO; ARELLANO, 2005), novas questões sobre a divulgação do conhecimento são apresentadas. Se, por um lado, vislumbram-se novas oportunidades de desenvolvimento em decorrência da visibilidade provocada pelo acesso global aos resultados de pesquisa, por outro, a publicação em repositórios de pré-prints pode significar a impossibilidade da obtenção posterior de patente. Ou seja, as tecnologias da informação e da comunicação não parecem fazer convergir para um modelo único de comunicação científica e tecnológica.

As relações entre ciência e tecnologia são muitas vezes abordadas pela literatura, uma vez que elas podem complementar-se. Conforme Teixeira (1996, p.32):

A tecnologia surge a partir da ciência, mas sobrevive pelo mercado. Pela aplicação da Lei de Paretto, diz-se que $20 \%$ das inovações tem sua origem na ciência e $80 \%$ 
no mercado. Dos $20 \%$ relativos à ciência, $80 \%$ produzem resultados, enquanto que dos $80 \%$ do mercado, apenas $20 \%$ fornecem resposta imediata.

Percebe-se, assim, a relação entre informação científica e tecnológica, pois a ciência é o subsídio fundamentado para que a inovação ocorra com sucesso, o que se concretiza, principalmente, através das pesquisas realizadas em universidades. Este fato é reforçado à medida que vários modelos propostos para definir o processo de inovação afirmam que a informação (não somente a científica) é o principal ingrediente para a inovação. (ALBUQUERQUE, 2000; BARBOSA, 1999; TEIXEIRA, 1996).

Spinak (2003) afirma que a idéia clássica que existe um modelo linear que vincula a ciência básica com a tecnologia: ciência $\rightarrow$ tecnologia $\rightarrow$ economia, é simplista e inexata, pois ignora a relação de retroalimentação que existe entre a ciência e a tecnologia. Assim, a produção do conhecimento dá-se de forma complexa e interligada.

Levando-se em consideração essa complexidade, mas, ao mesmo tempo, atendo-se a indicadores específicos, analisa-se o caso particular da primeira patente da UFRGS.

\section{ANÁLISE DA PRODUÇÃo CIENTÍFICA E TECNOLÓGICA}

Coronado Guerreiro, Acosta Seró e Marín Muñoz (2003) abordam o papel da universidade como elemento de um sistema de inovação, partindo de uma concepção moderna da universidade, na qual ela desempenha três funções essenciais: primeiro, lidera o processo geral de investigação científica, que afeta a fronteira tecnológica da indústria em longo prazo; segundo, gera um tipo de conhecimento que é diretamente aplicável aos processos industriais de produção; terceiro, proporciona os inputs principais do processo de inovação industrial - os recursos humanos que se incorporam à indústria e os investigadores destas instituições que colaboram com o setor privado industrial. Para que este modelo possa ser implementado, considera-se fundamental a realização de estudos que venham elucidar a relação ciência e tecnologia no âmbito da universidade, através da análise da produção científica e tecnológica de seus pesquisadores.

Dentro deste enfoque, investiga-se a produção intelectual que antecedeu ao processo de registro de uma patente, de autoria de três pesquisadores da UFRGS e que se configura como a primeira patente obtida por esta Universidade, além da produção intelectual posterior à publicação do pedido da mesma. O estudo objetiva encontrar relações entre a produção científica dos pesquisadores e esta patente, ou seja, analisar o fluxo existente entre a 
informação científica e a informação tecnológica, assim como o fluxo inverso. Para isto, analisou-se o conteúdo da carta-patente, de forma a extrair as palavras-chave que o identificam. Após essa fase, foram estudados os currículos dos pesquisadores envolvidos, disponíveis na Plataforma Lattes (CNPq).

Dois foram os aspectos levantados nos currículos: a produção científica e tecnológica destes pesquisadores e a ocorrência das palavras-chave da patente, anteriormente identificadas, nos títulos da produção intelectual. Procurou-se identificar a existência de um fluxo entre a informação científica e a tecnológica e vice-versa. O período definido foram os cinco anos anteriores ao processo de patenteamento, que correspondeu aos anos de 1996 a 2000 e os cinco anos posteriores, de 2001 a 2005.

Os resultados e as considerações do levantamento dos dados são mostrados e explanados nos quadros seguintes. O primeiro quadro apresenta dados sobre a produção científica e tecnológica dos autores da patente selecionada no período anterior à publicação do pedido de patente.

\begin{tabular}{|l|c|c|c|c|c|}
\hline & $\begin{array}{c}\text { Artigos: } \\
\text { Completos/ } \\
\text { Resumos }\end{array}$ & $\begin{array}{c}\text { Trabalhos em } \\
\text { Eventos: } \\
\text { Completos } \\
\text { Resumos }\end{array}$ & $\begin{array}{c}\text { Livros/ } \\
\text { Capítulos }\end{array}$ & $\begin{array}{c}\text { Processos ou } \\
\text { Técnicas }\end{array}$ & Outros \\
\hline Pesquisador 1 & 16 & 17 & 2 & 0 & 0 \\
\hline Pesquisador 2 & 32 & 92 & 9 & 0 & 5 \\
\hline Pesquisador 3 & 0 & 4 & 0 & 0 & 0 \\
\hline
\end{tabular}

Quadro 1: Produção científica e tecnológica dos pesquisadores envolvidos com o registro da patente: "Processo de Clareamento de Manchas e Ação Fungicida e Bactericida em Grãos e Sementes”, no período 1996-2000. Fonte: Plataforma Lattes. Disponível em: Http://www.cnpq.br

O levantamento da produção científica e tecnológica dos pesquisadores, em termos numéricos, demonstra que a produção de dois deles é significativa. Em uma análise individual é possível visualizar, por exemplo, a produção expressiva do Pesquisador 2, com um total de 92 trabalhos apresentados em eventos, e 32 artigos completos ou resumo (quer seja de autoria individual ou coletiva), muitos relacionados ao tema da patente, conforme se verá a seguir. A produção deste pesquisador totalizou, nesses 5 anos, 27,6 trabalhos ao ano. A mesma observação pode ser feita com relação ao pesquisador 1, com 35 trabalhos divulgados, totalizando 7 trabalhos ao ano. Ao se cruzar estes dados com as informações do Currículo Lattes dos pesquisadores, pode-se verificar que o pesquisador 3, neste período, era doutorando, com participação nas pesquisas dos outros dois pesquisadores, mais experientes.

Um destaque a ser feito é o alto número de trabalhos apresentados em eventos, o que parece ser uma preferência na área, para a comunicação científica aos seus pares. Tal fato é corroborado pelo trabalho de Mueller (2005) que identifica a preferência dos pesquisadores da 
área das Ciências Agrárias pela apresentação de trabalhos em eventos, principalmente nacionais. Outra preferência destacada pela autora é em relação à publicação em periódicos nacionais, em detrimento ao periódico estrangeiro.

Novamente, em relação ao quadro 1, na coluna Outros encontram-se os produtos tecnológicos, com um total de 5 para o pesquisador 2, o que demonstra a sua inclinação para a aplicação prática dos conhecimentos.

No quadro 2 a seguir, observa-se a produção científica e tecnológica dos pesquisadores, autores da patente já citada, no período posterior à publicação do pedido de patente.

\begin{tabular}{|l|c|c|c|c|c|}
\hline & $\begin{array}{c}\text { Artigos: } \\
\text { Completos/ } \\
\text { Resumos }\end{array}$ & $\begin{array}{c}\text { Trabalhos em } \\
\text { Eventos: } \\
\text { Completos/ } \\
\text { Resumos }\end{array}$ & $\begin{array}{c}\text { Livros/ } \\
\text { Capítulos }\end{array}$ & $\begin{array}{c}\text { Processos ou } \\
\text { Técnicas }\end{array}$ & Outros \\
\hline Pesquisador 1 & 12 & 24 & 3 & 1 & \\
\hline Pesquisador 2 & 18 & 97 & 6 & & $\begin{array}{c}\text { (produtos } \\
\text { tecnológicos) }\end{array}$ \\
\hline Pesquisador 3 & 17 & 14 & 0 & 1 & \\
\hline
\end{tabular}

Quadro 2: Produção científica e tecnológica dos pesquisadores envolvidos com o registro da patente: "Processo de Clareamento de Manchas e Ação Fungicida e Bactericida em Grãos e Sementes”, no período 2001-2006.

Fonte: Plataforma Lattes. Disponível em: Http://www.cnpq.br

No período posterior à publicação do pedido, observa-se, também, uma produção significativa dos pesquisadores, principalmente do pesquisador 2, com 97 trabalhos apresentados em eventos. A produção deste pesquisador totalizou, nesses 5 anos, 22,2 trabalhos ao ano, havendo um leve declínio em relação ao período anterior. O pesquisador 1 também teve uma produção significativa, com 24 trabalhos apresentados em eventos e 12 artigos publicados em revistas. A produção deste pesquisador totalizou, nesses 5 anos, 8 trabalhos ao ano, havendo um pequeno acréscimo em relação ao período anterior. $\mathrm{O}$ pesquisador número 3 foi o que demonstrou um maior aumento na produção, na comparação entre os dois períodos. Isto pode ser atribuído à conclusão do seu doutorado e seu ingresso no pós-doutorado.

Quanto à opção Patentes, apenas o pesquisador 1 e 3 registraram em seus currículos esta produção, o que conflitua com a autoria da carta-patente, em nome dos três pesquisadores. Por outro lado, o pesquisador 2 registrou outros dois produtos tecnológicos, sem relação com a patente citada. Ressalta-se que este pesquisador incluiu a patente em questão no item produtos tecnológicos do Currículo Lattes, com a data de 1999.

Os quadros seguintes apresentam a análise da relação entre a produção intelectual dos três autores da patente e as palavras-chave retiradas do título e do conteúdo do documento de 
patente. Esta análise objetivou identificar se os assuntos abordados no documento-patente o foram também em publicações científicas nos períodos anterior e posterior ao registro da patente. A ocorrência das palavras-chave nos títulos definiu sua inclusão nos quadros.

\begin{tabular}{|c|c|c|c|c|c|}
\hline Palavras-chave & \begin{tabular}{|l} 
Artigos: \\
Completos/ \\
Resumos
\end{tabular} & $\begin{array}{c}\text { Trabalhos } \\
\text { em Eventos: } \\
\text { Completos/ } \\
\text { Resumos }\end{array}$ & \begin{tabular}{|c} 
Livros/ \\
Capítulos
\end{tabular} & \begin{tabular}{|c} 
Processos \\
ou \\
Técnicas
\end{tabular} & Outros \\
\hline $\begin{array}{l}\text { Manchas / Clareamento } \\
\text { Incluindo: Hipoclorito de Sódio/Íon } \\
\text { Hipoclorito/Cálcio }\end{array}$ & $\begin{array}{l}\mathrm{P} 1=3 \\
\mathrm{P} 2=0 \\
\mathrm{P} 3=0\end{array}$ & $\begin{array}{l}\mathrm{P} 1=1 \\
\mathrm{P} 2=0 \\
\mathrm{P} 3=1\end{array}$ & $\begin{array}{l}\mathrm{P} 1=0 \\
\mathrm{P} 2=0 \\
\mathrm{P} 3=0\end{array}$ & $\begin{array}{l}\mathrm{P} 1=0 \\
\mathrm{P} 2=0 \\
\mathrm{P} 3=0\end{array}$ & $\begin{array}{l}\mathrm{P} 1=0 \\
\mathrm{P} 2=1 \\
\mathrm{P} 3=0\end{array}$ \\
\hline $\begin{array}{l}\text { Fungos/Bactérias } \\
\text { Incluindo: Pyrenophora } \\
\text { avenae/Ferrugem da folha }\end{array}$ & $\begin{array}{l}\mathrm{P} 1=6 \\
\mathrm{P} 2=5 \\
\mathrm{P} 3=0\end{array}$ & $\begin{array}{l}\mathrm{P} 1=18 \\
\mathrm{P} 2=23 \\
\mathrm{P} 3=3\end{array}$ & $\begin{array}{l}\mathrm{P} 1=1 \\
\mathrm{P} 2=0 \\
\mathrm{P} 3=0\end{array}$ & $\begin{array}{l}\mathrm{P} 1=0 \\
\mathrm{P} 2=0 \\
\mathrm{P} 3=0\end{array}$ & $\begin{array}{l}\mathrm{P} 1=4 \\
\mathrm{P} 2=1 \\
\mathrm{P} 3=0\end{array}$ \\
\hline $\begin{array}{l}\text { Grãos/Sementes } \\
\text { Incluindo: Aveia/ Trigo /Cevada } \\
\text { /Soja /Milho }\end{array}$ & $\begin{array}{l}\mathrm{P} 1=13 \\
\mathrm{P} 2=26 \\
\mathrm{P} 3=0\end{array}$ & $\begin{array}{l}\mathrm{P} 1=15 \\
\mathrm{P} 2=88 \\
\mathrm{P} 3=2\end{array}$ & $\begin{array}{l}\mathrm{P} 1=1 \\
\mathrm{P} 2=7 \\
\mathrm{P} 3=0\end{array}$ & $\begin{array}{l}\mathrm{P} 1=0 \\
\mathrm{P} 2=0 \\
\mathrm{P} 3=0\end{array}$ & $\begin{array}{l}\mathrm{P} 1=1 \\
\mathrm{P} 2=5 \\
\mathrm{P} 3=0\end{array}$ \\
\hline
\end{tabular}

Quadro 3: Produção científica dos pesquisadores relacionada aos assuntos da patente "Processo de Clareamento de Manchas e Ação Fungicida e Bactericida em Grãos e Sementes”, abrangendo o período de 1996 a 2000. Fonte: Dos autores.

\begin{tabular}{|l|l|l|l|l|l|}
\hline Palavras-chave & $\begin{array}{c}\text { Artigos: } \\
\text { Completos/ } \\
\text { Resumos }\end{array}$ & $\begin{array}{c}\text { Trabalhos } \\
\text { em Eventos: } \\
\text { Completos/ } \\
\text { Resumos }\end{array}$ & $\begin{array}{c}\text { Livros/ } \\
\text { Capítulos }\end{array}$ & $\begin{array}{c}\text { Processos } \\
\text { ou } \\
\text { Técnicas }\end{array}$ & Outros \\
\hline $\begin{array}{l}\text { Manchas / Clareamento } \\
\text { Hipcluindo: Hipoclorito de Sódio/Íon }\end{array}$ & $\mathrm{P} 1=3$ & $\mathrm{P} 1=3$ & $\mathrm{P} 1=0$ & $\mathrm{P} 1=2$ & $\mathrm{P} 1=0$ \\
& $\mathrm{P} 2=31$ & $\mathrm{P} 2=1$ & $\mathrm{P} 2=0$ \\
$\mathrm{P} 3=7$ & $\mathrm{P} 3=0$ & $\mathrm{P} 3=0$ & $\mathrm{P} 2=0$ \\
$\mathrm{P} 3=0$
\end{tabular}

Quadro 4: Produção científica dos pesquisadores relacionada aos assuntos da patente "Processo de Clareamento de Manchas e Ação Fungicida e Bactericida em Grãos e Sementes", abrangendo o período de 2001 a 2006. Fonte: Dos autores.

A produção científica dos pesquisadores, no que se refere aos assuntos que a patente aborda, demonstra que, antes do processo de registro da patente, o tema foi extensivamente abordado em trabalhos científicos, divulgados em eventos, artigos de periódicos ou livros. Novamente, destaca-se, em números absolutos, a apresentação de trabalhos em eventos.

Percebe-se que o cerne da produção encontra-se na área de grãos e sementes, mais especificamente aveia, seguido da área fungos e bactérias, mais pontualmente Pyrenophora avenae. 
Os dados indicam que ocorre um fluxo entre a informação científica e a tecnológica, na qual a primeira foi debatida entre os pares, tanto no âmbito da publicação formal, como da informal, especialmente em eventos específicos da área. A opção 'Outras' refere-se somente a produção tecnológica.

Analisando o número de trabalhos divulgados pelos pesquisadores no período posterior ao registro do pedido, verifica-se que não houve um acréscimo significativo de trabalhos relativos ao tema abordado pela patente analisada neste estudo. Para exemplificar, no período anterior, o pesquisador 2 divulgou 92 trabalhos em eventos, sendo que 111 palavras-chaves se referiam ao tema da patente, totalizando uma média de 1,20 palavraschaves por trabalho. No período posterior, este mesmo pesquisador divulgou 97 trabalhos em eventos, sendo que 91 palavras-chaves se referiam ao tema da patente, perfazendo um total de 0,93 palavras-chaves por trabalho, o que demonstra que houve um leve declínio no número de trabalhos apresentados em eventos que sejam especificamente relacionados com os assuntos abordados na patente analisada neste estudo.

Em relação à publicação em artigos, no período anterior ao do registro do pedido da patente, observa-se que este pesquisador (pesquisador 2) publicou 32 artigos em periódicos, sendo que 31 palavras-chaves destes artigos são referentes ao assunto da patente, em uma média de 0,96 palavras-chaves por artigo.

Já no período posterior, o mesmo pesquisador obteve um total de 18 artigos publicados em revistas, sendo que 55 palavras-chaves se referem ao tema da patente, totalizando uma média de 3,05 palavras-chaves por artigo. Na comparação com o período anterior, pode-se inferir que estes artigos são resultado do grande número de apresentações em eventos que foram realizadas naquele período, confirmando o fluxo da informação cientifica, no qual um trabalho apresentado em evento evolui para uma publicação em artigo de periódico, em um processo seqüencial.

O pesquisador 1 , no período anterior, publicou 16 artigos, sendo que 22 palavraschave se referem ao tema da patente, totalizando uma média de 1,3 palavras-chave por artigo. Já no período posterior, este mesmo pesquisador publicou 12 artigos, sendo que 26 palavraschave se referem ao tema da patente, totalizando uma média de 2,16 palavras-chave por artigo.

Em relação à apresentação em eventos, o pesquisador 1 apresentou 17 trabalhos no período anterior, sendo que 34 palavras-chave se referem ao tema da patente, fazendo uma média de 2 palavras-chave por artigo. Já no período posterior, este mesmo pesquisador 
apresentou 24 trabalhos em eventos, sendo que 47 palavras-chave referem-se ao tema da patente, totalizando uma média de 1,95 palavras-chave por artigo.

Já o pesquisador 3, alcançou os seguintes percentuais: no período anterior à publicação do pedido da patente, não possuía nenhum artigo publicado, mas apresentou 4 trabalhos em eventos, sendo que 6 palavras-chave referiam-se ao assunto da patente, fazendo uma média de 1,5 palavras-chave por artigo. E no período posterior, este pesquisador publicou 17 artigos, sendo que 19 palavras-chave se relacionam com o tema da patente, totalizando uma média de 1,11 palavras-chave por artigo. Em eventos, foram apresentados 14 trabalhos, sendo que 30 palavras-chave referem-se ao tema da patente, totalizando uma média de 2,14 palavras-chave por artigo.

Comparando estes dados com o quadro anterior, percebe-se que o assunto referente à patente foi mais divulgado antes da publicação do pedido da patente do que no período posterior. Este dado surpreende, partindo-se do pressuposto que, após a obtenção da carta, os pesquisadores poderiam divulgar dados que, talvez, antes não pudessem ser revelados, pois aguardavam a sua proteção ser obtida. Surpreende, também, o fato do tema ser amplamente divulgado antes de ocorrer a proteção, o que, baseado na literatura consultada, leva a entender que tal procedimento poderia ter inviabilizado o processo de patenteamento do invento. Entende-se, desta forma, que houve uma publicação sobre o tema, mas não dos dados específicos que levariam à obtenção da carta-patente. Isto pode demonstrar que, embora a patente tenha sido protegida, ainda se faz necessário proteger alguns dados, uma vez que é de conhecimento que a divulgação das informações em uma patente não revelam todas as informações necessárias à implementação de um invento.

\section{CONCLUSÕES}

É inegável a importância dos documentos de patentes como subsídio à construção do conhecimento científico e tecnológico. No entanto, é necessário compreender como ocorre o fluxo de informações entre ciência e tecnologia.

No caso analisado nesse estudo, pode-se perceber que existe uma relação entre a produção do conhecimento científico e do tecnológico, ocorrendo um fluxo entre eles, o qual foi constatado por meio da ocorrência de palavras-chave que se referem ao tema da patente na produção bibliográfica dos pesquisadores, tanto no período anterior como no posterior ao 
registro do pedido, o que indica tanto o impacto da ciência na tecnologia como o da tecnologia na ciência.

Constatou-se que os pesquisadores que obtiveram a primeira carta-patente da UFRGS têm alta produtividade, com exceção de um que, na época, era aluno de doutorado. O destaque fica para o pesquisador 2, que obteve uma média de 27,6 trabalhos ao ano no período anterior ao registro do pedido de patente e 22,2 no período posterior. Este dado reforça a importância da realização de pesquisas como subsídio para o desenvolvimento tecnológico.

Para pelo menos um dos pesquisadores (pesquisador 2), os dados demonstram que os artigos publicados em revistas no período posterior possuem uma relação maior com a patente, pois há uma maior ocorrência de termos referentes aos temas pertinentes a ela. $\mathrm{O}$ mesmo não aconteceu com trabalhos apresentados em eventos, nos quais houve uma diminuição da incidência de palavras-chave.

A apresentação do trabalho primeiro em evento e posterior publicação em periódico reforça o fluxo da comunicação científica tradicional. Também se confirmou a preferência da área de Agronomia pela apresentação de trabalhos em eventos, embora esses dados não possam ser generalizados para além do âmbito deste estudo, pois o universo de investigação é restrito.

A análise leva a concluir que mais pesquisas devem ser realizadas, uma vez que no Brasil, praticamente, não há estudos nessa linha. Desta forma, pretende-se replicar esta mesma metodologia às demais cartas-patente da instituição, registradas no INPI, e aos pesquisadores nelas envolvidos, ampliando o estudo.

Além disto, entrevistas aos pesquisadores permitirão elucidar questões, que nesta análise não puderam ser aprofundadas, como por exemplo, a efetiva relação entre a produção intelectual divulgada e o documento de patente.

\section{REFERÊNCIAS}

ALBUQUERQUE, Eduardo da Motta e. Informação, Conhecimento e Apropriação: notas sobre o significado econômico das patentes e os impactos da emergência de uma economia baseada no conhecimento. Perspectivas em Ciência da Informação, Belo Horizonte, v. 5, n. 2, p. 243-254, jul./dez. 2000.

ALVARES, Lílian Maria Araújo de Rezende. Informação Tecnológica: discussão acerca da atualização do conceito. Revista de Biblioteconomia de Brasília, Brasília, v. 22, n. 1, p 4770, jan./jun. 1988. 
ARAÚJO, Vânia Maria Rodrigues Hermes de. Uso da Informação Contida em Patentes nos Países em Desenvolvimento. Ciência da Informação, Brasília, DF, v. 13, n. 1, p. 53-56, jan./jun. 1984.

BARbosA, A. L. Figueira. Sobre a Propriedade do Trabalho Intelectual. Rio de Janeiro: Editora UFRJ, 1999.

BUAINAIN, Antonio Marcio, CARVALHO, Sergio M. Paulino de, PAULINO, Sonia Regina, YAMAMURA, Simone. Propriedade Intelectual e Inovação Tecnológica: algumas questões para o debate atual. [S.1: S.n.] , [2003?]. Disponível em:

$<$ www.desenvolvimento.gov.br/arquivo/sti/publicacoes/futAmaDilOportunidades/futIndustria 2_00.pdf >. Acesso em: 22 jun. 2006.

CORONADO GUERRERO, Daniel; ACOSTA SERÓ, Manuel; MARÍN MUÑOZ, Rosario. La Contribución de la Universidad al Desarrollo de Tecnología Industrial. Diferencias sectoriales, regionales y factores determinantes. In: REUNIÓN DE ESTUDIOS REGIONALES, 30., 2003. Santander . [S.n.], 27 y 28 nov. 2003. Anales electrônicos.... Disponível em: $<$ http://www.aecr29.unican.es/paginas/Programa.htm>. Acesso em: 20 jun. 2005.

COSTA, Sely M. S. Mudanças no Processo de Comunicação Científica: o impacto do uso de novas tecnologias. In: MUELLER, Suzana Pinheiro Machado; PASSOS, Edilenice Jovelina Lima. Comunicação Científica. Brasília: Departamento de Ciência da Informação/ Universidade de Brasília, 2000. P. 85-105.

FRANÇA, Ricardo Orlandi. A Patente. In: CAMPELLO, B. S.; CENDÓN, B. V.; KREMER, J. M. (Orgs.). Fontes de Informação para Pesquisadores e Profissionais. Belo Horizonte: Editora UFMG, 2000. P. 153-182.

MORENO, Fernanda Passini; ARELLANO, Miguel Ángel Márdero. Publicação Científica em Arquivos de Acesso aberto. Arquivística.net-, Rio de Janeiro, v. 1, n. 1, p. 76-86, jan./.jun. 2005. Disponível em:

$<$ http://www.arquivistica.net/ojs/include/getdoc.php?id $=53 \&$ article $=5 \&$ mode $=$ pdf $>$. Acesso em: 26 jun. 2006.

MUELLER, Suzana Pinheiro Machado. A Publicação da Ciência: áreas científicas e seus canais preferenciais. DataGramaZero - Revista de Ciência da Informação, v. 6, n. 1, fev. 2005. Disponível em: <http://www.dgzero.org/fev05/Art_02.htm>. Acesso em: 08 abr. 2005.

SPINAK, Ernesto. Indicadores Cienciométricos de Patentes: aplicaciones y limitaciones. Madrid: [S.n.], mar.2003. Disponível em:

$<$ http://www.ricyt.org/interior/normalizacion/III_bib/Spinak.pdf $>$. Acesso em: 20 jun.2005.

SILVA, Edna Lúcia da; MENEZES, Estera Muszkat; PINHEIRO, Liliane Vieira. Avaliação da Produtividade Científica dos Pesquisadores das Áreas de Ciências Humanas e Sociais Aplicadas. Informação e Sociedade, João Pessoa, v. 13, n. 2, p. 1-18, 2003.

STUMPF, Ida Regina Chittó. A Comunicação da Ciência na Universidade: o caso da UFRGS. In: MUELLER, Suzana Pinheiro Machado; PASSOS, Edilenice Jovelina Lima. 
Comunicação Científica. Brasília: Departamento de Ciência da Informação / Universidade de Brasília, 2000. P. 107-121.

SUBER, Peter. Removing barriers to research: an introduction to open access for librarians. College \& Research Libraries News, v. 64, n. 2, p. 92-94, 113 Feb. 2003. Disponível em: http://vnweb.hwwilsonweb.com/hww/results/external_link_maincontentframe.jhtml?_DARG $\mathrm{S}=/$ hww/results/results_common.jhtml.9. Acesso em: 26 jun. 2006.

TEIXEIRA, Maria do Rocio Fontoura. O Uso da Informação de Patentes no Planejamento Estratégico de Empresas Industriais: um caso aplicado ao setor de produtos de higiene pessoal e perfumaria. Dissertação (Mestrado em Administração)- Programa de Pós-graduação em Administração, Universidade Federal do Rio Grande do Sul, Porto Alegre, 1996.

THE UNITED KINGDON PARLIAMENT. Science and technology tenth report. London: House of Commons, 2004. Disponível em: <http://www.publications.parliament.uk/pa/ cm200304/cmselect/cmsctech/399/39902.htm> Acesso em: 26 jun. 2006.

\begin{abstract}
The paper discusses intellectual and industrial property and existing differences between scientific and technological knowledge. It aims at incorporating the patent in the context of the scientific and technological communication. It presents preliminary data of a study that aims at analyzing the relationship between scientific and technological information in the intellectual production of the researchers-inventors of the first patent from the Federal University of Rio Grande do Sul (UFRGS). It concludes that, in the case studied, a flow between scientific and technological information occurs, in which the former, after its diffusion and approval in the peer review process, subsidizes the latter. It suggests that other studies should be carried out.
\end{abstract}

KEYWORDS: Patents. Intellectual Property. Industrial Property. Scientific Communication. Scientific Production.

Originais recebidos em 06/04/2006. 